\title{
Assessing Walking and Cycling around Schools
}

\author{
Khaled Shaaban ${ }^{1, *(\mathbb{D})}$ and Khadija Abdur-Rouf ${ }^{2}$ (D) \\ 1 Department of Engineering, Utah Valley University, 800 W University Pkwy, Orem, UT 84058, USA \\ 2 Department of Civil Engineering, Qatar University, P.O. Box 2713 Doha, Qatar; kb1606107@qu.edu.qa \\ * Correspondence: kshaaban@uvu.edu
}

Received: 4 October 2020; Accepted: 10 December 2020; Published: 18 December 2020

\begin{abstract}
To encourage students to walk and cycle to school and ensure their health and safety, it is essential to provide safe and operationally efficient infrastructure around schools. This study used an audit tool to assess the infrastructure and environment around schools in the city of Doha, Qatar, with a particular emphasis on active transport (walking and cycling). The aim was to identify strengths, weaknesses, and areas for improvement. Twenty-two schools with varied education levels were assessed. Among all assessed categories, active transport items scored the lowest, requiring the most improvements. A detailed analysis was conducted based on school type (elementary, primary, high, and mixed-schools) and revealed similar results except for elementary schools (scored acceptable for active transport). The study revealed that adding bike lanes, installing bicycle parking, and providing good separation of travel modes are the most needed improvements at school sites. In summary, improving active transport could significantly improve the overall quality of the infrastructure around schools in Qatar. Such improvements could greatly encourage more school children to walk and cycle to school instead of being primarily dropped-off and picked up by their parents' vehicles or school buses.
\end{abstract}

Keywords: built environment; active transport; traffic safety; active commuting; physical activity

\section{Introduction}

As indispensable institutions in any community, schools require well-planned and well-connected infrastructure. Selecting appropriate school sites and ensuring safe routes and efficient school designs within communities could improve children's school performance and instill in them lifelong healthy habits, such as active transportation [1]. Active transportation around schools is defined as school children's ability to choose to walk or cycle as part of their travel to school. Macro-environmental factors (design, density, and diversity of land use), micro-environmental features (pedestrian-friendly designs), and parents' and children's perceptions of walking or cycling to school are some of the main barriers to modes of active transportation to and from school [2,3].

Moreover, traffic exposure also influences parents' and children's perceptions of active transportation. Studies have shown that high street connectivity combined with low traffic exposure could increase neighborhood walkability and encourage more children to walk or cycle regularly to school $[4,5]$. While well-connected road networks can offer direct access to schools, they also increase the probability of traffic accidents and injury to those who are directly associated with schools, especially school children [6]. Unsurprisingly, high traffic exposure and low street connectivity have the opposite effect [6,7]. It is, therefore, essential to provide environmentally safe and operationally efficient infrastructure around schools to ensure children's safety while walking or cycling to school.

To that end, it is necessary to constantly evaluate the infrastructure around schools to identify problems and provide solutions. The main objective of this study was to assess the walkability, safety, and efficiency of schools in Qatar, a high-income developing country in the Arabian Gulf region. More 
specifically, the study aimed to identify strengths and weaknesses and provide recommendations for overall and specific improvements for different types of schools (elementary, middle, high, and mixed-schools), to find ways of getting children more physically active and increasing active school transportation. A comprehensive assessment of schools in Qatar or the Arabian Gulf region was not found in the literature; therefore, the evaluation of different types of schools in Qatar was found to be both essential and timely.

\section{Literature Review}

\subsection{Walking and Cycling around Schools in Qatar}

People in high-income developing countries such as Qatar walk and cycle less compared to developed countries due to several reasons including weather conditions [8-10], inadequate active transportation infrastructure [11-14], and traffic safety concerns [15-17]. For these reasons, school students are more dependent on their parents, private vehicles driven by chauffeurs, and school buses. A study surveying five schools in Qatar found that approximately $1 \%$ of children walked or cycled to school [18]. Fifty-eight percent were driven to school by a parent or driver, while $38 \%$ traveled by school bus. The high percentage of students transported by private vehicles is surprising. Despite its limited sample size, this study provides insight into school transportation mode preferences in Qatar. Parents' concerns regarding the lack of proper infrastructure, young children's lack of danger perception, girls walking alone or mixing with boys, and temperatures frequently exceeding $35^{\circ} \mathrm{C}$ could be reasons that active transportation is a largely unattractive mode choice for traveling to and from school [18]. In Qatar, various types of schools can be identified according to education level (elementary, middle, high school, or mixed). Therefore, it is necessary to evaluate them from various perspectives to identify prevalent weaknesses specific to certain school types. Identifying and improving the infrastructure around schools can play a major role in promoting walking and cycling.

\subsection{Strategies to Improve Infrastructure around Schools}

There are several infrastructure-related strategies that could be implemented to increase active transportation among school students. A program in Colorado (safe routes to school) involving the improvement of several infrastructure urban-design elements was implemented to increase walking and biking to school. After the implementation of the program in an elementary school, $45 \%$ more students living within 2 miles of the school, walked or biked daily instead of using a car $[19,20]$. Additionally, street-scale urban design strategies focusing on improving or introducing street lighting, street crossings, traffic calming devices, streetscape, and sidewalk continuity has proven to encourage physical activity within a few blocks [21]. Likewise, in an initiative in the City of Toronto, the reconfiguration of 2 of the 4 motor travel lanes into $40 \mathrm{~km}$ long stretch of bicycle lanes resulted in a $23 \%$ increase in bicycle trips [22]. Similarly, other successful policies include modifying roadway design standards, increasing costs of parking, and making public transportation more accessible for bicycle users [23].

In short, to encourage physical activity within a few kilometers range, infrastructure improvement such as developing or improving sidewalks, bicycle lanes, street connectivity, and mixed land-use promoting the use of active transport to reach destinations are needed. Therefore, there is a need for proper assessment tools to evaluate the infrastructure around schools from various perspectives to identify prevalent weaknesses specific to specific school types.

\subsection{School Audit Tools}

Several audit tools for assessing schools have been developed over the years focusing on walkability [2,6,24,25], active transport [26-28], walkability and active school transport [7], or walkability and safety [25,29]. Zhu, et al. [29] used a 14-item audit tool, divided into six categories, namely maintenance, visual quality, physical amenities, safety, and others, to assess street-level 
walkability [29]. Tarun et al., on the other hand, used the 39-item tool, developed [27] and validated in the UK [28], to assess the outdoor school environment and physical activity. The tool was categorized into six categories: access, surroundings, school grounds, aesthetics, usage, and general environment.

In contrast, the three-tier 22-item school audit tool developed by Lee et al., comprising of a street, school-site, and map-based audit tools offered a more comprehensive tool. The tool was based on the spatial Behavioral Model of Environment (BME) used by Moudon et al. [30] and Lee et al. [31] that links physical activity with different factors from the built environment $[30,31]$. The tool, however, did not include different important transport features related to the school environment, such as the road network and parking area. Consequently, the most recent 30-item tool developed by [32] is a simple, comprehensive, and straight-forward school audit tool that covers different audit items commonly used or recommended in the literature [32].

In developing countries, there is a need for a simple, adaptable, and comprehensive school audit tool. Since the SAT (school audit tool) was recently developed and validated in Qatar [32], the tool was selected for this study. This tool can be used for assessing safety (road network and school site characteristics) and efficiency (parking/loading facilities) of schools besides assessment of walkability (active transport elements). These items could be assessed together or separately as required. In this study, all items in the assessment tools were used in the analysis.

\subsection{Objectives}

The main objective of this study was to utilize an audit tool to assess walking and cycling infrastructure and environment around schools in the city of Doha, Qatar. More specifically, the study aimed to identify strengths and weaknesses then provide recommendations for overall and specific improvements, as well as improvements based on school type (elementary, middle, high, and mixed-schools). As part of the assessment, various aspects of the school sites (infrastructure and environment) that can affect the safety, health, and behavior of students were evaluated.

\section{Methodology}

\subsection{School Audit Tool (SAT)}

The 30-item audit tool, SAT, used in this study was recently developed by Shaaban et al [32] as an effective tool to assess the infrastructure around schools (see Table 1). In this tool, the items were sorted into four groups, namely school site, road network, parking-loading, and active transport. Each assessment group consisted of items that helped evaluate the major elements under that category most comprehensively. Moreover, a 4-point Likert-type scale was adopted in this tool to rate each item ordinally as 1 to 4 (undesirable, poor, acceptable, and good), making it possible to assess each item with ease, consistency, and detail across schools. A detailed description of the four ordinal scores for all items under the four assessment categories can be found in the SAT form [32]. 
Table 1. List of the 30-item in SAT.

\begin{tabular}{|c|c|c|c|}
\hline \multirow{30}{*}{$\begin{array}{c}\text { School Audit Tool (SAT) } \\
\text { 30-item }\end{array}$} & \multirow{7}{*}{$\begin{array}{l}\text { School Site } \\
\text { 7-item }\end{array}$} & S1 & Proximity to high-speed roads \\
\hline & & S2 & Presence of major roads \\
\hline & & S3 & Land-use in the surrounding area \\
\hline & & S4 & Fence around school \\
\hline & & S5 & Location of entrance \\
\hline & & S6 & Multiple access points to school \\
\hline & & S7 & Congestion problems \\
\hline & \multirow{7}{*}{$\begin{array}{l}\text { Road Network } \\
\text { 7-item }\end{array}$} & $\mathrm{R} 8$ & Speed limit signs \\
\hline & & R9 & School zone signing and pavement markings \\
\hline & & R10 & Speed reduction methods \\
\hline & & R11 & Road classification of the adjacent street \\
\hline & & $\mathrm{R} 12$ & Adequate sight distance \\
\hline & & R13 & Public bus accessibility \\
\hline & & R14 & Amenities for physically challenged students \\
\hline & \multirow{9}{*}{$\begin{array}{l}\text { Parking/Loading } \\
\text { 9-item }\end{array}$} & P15 & Adequate pick-up/drop-off zones for school buses \\
\hline & & P16 & Adequate queuing area \\
\hline & & P17 & Parking for service and emergency vehicles \\
\hline & & P18 & Staff parking \\
\hline & & P19 & Visitor parking \\
\hline & & $\mathrm{P} 20$ & Safety of parents \\
\hline & & $\mathrm{P} 21$ & Parking for high school students \\
\hline & & $\mathrm{P} 22$ & Traffic organization duty \\
\hline & & $\mathrm{P} 23$ & Parking problems \\
\hline & \multirow{7}{*}{$\begin{array}{l}\text { Active Transport } \\
\text { 7-item }\end{array}$} & A24 & Walking and biking conditions \\
\hline & & A25 & Availability of crosswalks \\
\hline & & A26 & Availability of sidewalks \\
\hline & & A27 & Availability of bike storage \\
\hline & & A28 & Availability of bike lanes \\
\hline & & A29 & Separation of travel modes \\
\hline & & A30 & Pedestrian problems \\
\hline
\end{tabular}

\subsection{Data Collection}

Two auditors independently collected the ratings for 22 schools within Doha, Qatar, with varying education levels (see Figure 1 for the locations of the sample schools). The randomly selected school samples $(n=22)$ comprised of a diverse mix of elementary, middle, and high schools (see Table 2 for a summary of the schools). Ten of the 22 schools were mixed-level schools, while the rest were single-level schools. A mixed-level school is a school that included two or more different levels in the same school: elementary/middle, middle/high, or elementary/middle/high. In Qatar, students in elementary school are aged at least between 4-11 years old, 12-14 years old in middle school, and 15-17 years old in high school [33]. For the mixed-level schools, seven schools provided all levels of education, two schools provided elementary/middle education, and one school provided middle/high education. For the single level schools, four schools provided elementary level education, six schools provided middle-level education, and two schools provided high-level education. 


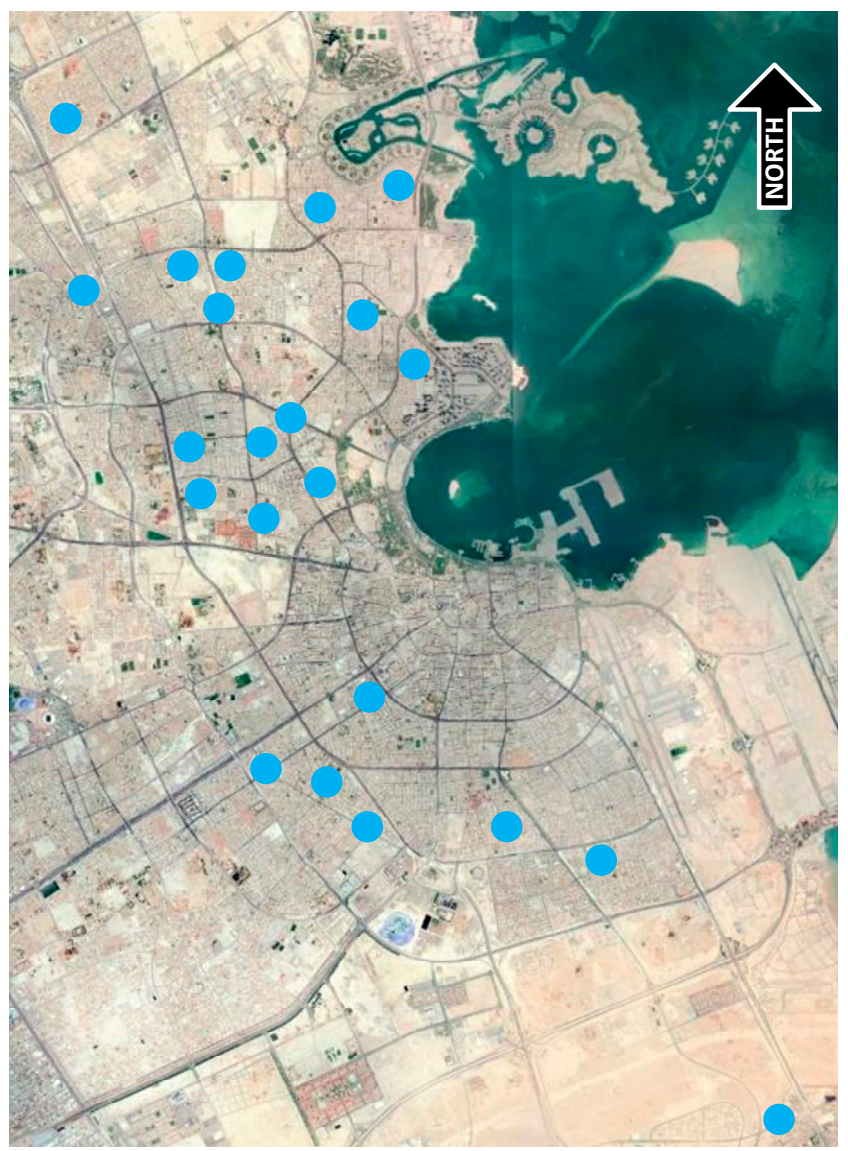

Figure 1. Location of randomly selected schools. (Source: Google Maps).

Table 2. Summary of the sample schools $(n=22)$.

\begin{tabular}{lc}
\hline \multicolumn{1}{c}{ School Name } & Level \\
\hline Al Bayan Education Complex for Girls & Elementary \\
Khawla Bint Al Azwar Independent Primary School for Girls & Elementary \\
Newton International School & Elementary \\
Doha English Speaking School & Elementary \\
Omar Bin Al Khattab Preparatory School for Boys & Middle \\
Hafsa Independent Preparatory School for Girls & Middle \\
Al Razi Preparatory Independent School for Boys & Middle \\
Al Wajba Preparatory Girls School & Middle \\
Amna Bint Wahab Preparatory School for Girls & Middle \\
Spectra Global School & Middle \\
Musab Bin Omair Secondary School & High \\
Umm Hakeem Independent School & High \\
Doha College & Elementary/Middle \\
Lycée Voltaire & Elementary/Middle \\
Al Andalus Preparatory \& Secondary School for Boys & Middle/High \\
Jawan Bin Jassim Model Independent School for Boys & Elementary/Middle/High \\
Middle East International School & Elementary/Middle/High \\
Cambridge International School & Elementary/Middle/High \\
Doha Modern Indian School & Elementary/Middle/High \\
American Academy School & Elementary/Middle/High \\
English Modern School & Elementary/Middle/High \\
Lebanese School & Elementary/Middle/High \\
\hline
\end{tabular}




\section{Analysis}

\section{Validation of the Audit Tool}

It was necessary to validate the audit tool before analyzing the results. Since the application of the 4-point Likert-type tool was largely observation and perception-based, intraclass correlation coefficients (ICCs) measure was used to check the inter-rater and test-retest reliability and robustness of the tool. This method has been used in previous studies as a method for validating school audit tools [24,29]. Accordingly, the tool was applied to the selected schools, and the item-by-item and categorical ICCs were measured. ICCs measures, ranging between 0 and 1, offer an overview of the degree of disagreement between independent ratings of the same schools done by two raters (inter-rater) and 2 independent ratings done by the same rater (test-retest) [24,29,34]. For instance, the absolute ICCs values 0 and 1 indicate random and perfect agreement respectively; values above 0.75 indicate good to excellent agreement; values below 0.60 indicate poor to fair agreement; values between 0.60 and 0.75 indicate moderate agreement [24,35]. Separate validation was conducted for each type of school (single versus mixed). The statistical analysis was performed using the SPSS software.

For single-level schools, the reliability statistical analysis showed good to excellent results for both tests (see Tables 3 and 4). Most of the 30 item-by-item ICCs in inter-rater and test-retest tests received a score of 0.75 or more. Ratings of three items (public bus accessibility, parking for high school students, and availability of bike lanes) in the inter-rater test and seven items (proximity to high-speed roadway, land-use in surrounding area, speed reduction methods, road classification of adjacent street, amenities for physically challenged students, adequate bicycle storage, and availability of bike lanes) in the test-retest test were in complete match $(\mathrm{ICC}=1)$.

Table 3. Results of categorical item-by-item inter-rater reliability tests.

\begin{tabular}{|c|c|c|c|c|c|c|c|c|}
\hline \multirow{3}{*}{ Item } & \multicolumn{4}{|c|}{ Single-Level Schools } & \multicolumn{4}{|c|}{ Mixed-Level Schools } \\
\hline & \multirow{2}{*}{ ICC } & \multicolumn{2}{|c|}{$95 \%$ CI } & \multirow{2}{*}{$p$-Value } & \multirow{2}{*}{ ICC } & \multicolumn{2}{|c|}{$95 \% \mathrm{CI}$} & \multirow{2}{*}{$p$-Value } \\
\hline & & Lower Limit & Upper Limit & & & Lower Limit & Upper Limit & \\
\hline S1 & 0.916 & 0.708 & 0.976 & $<0.0001$ & 0.900 & 0.597 & 0.975 & 0.001 \\
\hline S2 & 0.896 & 0.637 & 0.970 & $<0.0001$ & 0.853 & 0.407 & 0.963 & 0.004 \\
\hline S3 & 0.959 & 0.857 & 0.988 & $<0.0001$ & 0.926 & 0.701 & 0.982 & $<0.0001$ \\
\hline S6 & 0.762 & 0.173 & 0.931 & 0.013 & 0.882 & 0.523 & 0.971 & 0.002 \\
\hline S7 & 0.596 & -0.404 & 0.884 & 0.074 & 0.677 & -0.299 & 0.920 & 0.054 \\
\hline \multicolumn{9}{|c|}{ Road Network } \\
\hline R8 & 0.983 & 0.941 & 0.995 & $<0.0001$ & 0.987 & 0.947 & 0.997 & $<0.0001$ \\
\hline R9 & 0.978 & 0.924 & 0.994 & $<0.0001$ & 1.000 & - & - & - \\
\hline $\mathrm{R} 14$ & 0.932 & 0.764 & 0.980 & $<0.0001$ & 0.810 & 0.233 & 0.953 & 0.011 \\
\hline \multicolumn{9}{|c|}{ Parking Loading } \\
\hline P15 & 0.767 & 0.190 & 0.933 & 0.012 & 0.710 & -0.167 & 0.928 & 0.571 \\
\hline P16 & 0.827 & 0.397 & 0.950 & 0.004 & 0.591 & -0.648 & 0.898 & 0.1 \\
\hline P17 & 0.877 & 0.573 & 0.965 & 0.001 & 0.837 & 0.345 & 0.960 & 0.006 \\
\hline P18 & 0.917 & 0.711 & 0.976 & $<0.0001$ & 0.868 & 0.470 & 0.967 & 0.003 \\
\hline P19 & 0.934 & 0.771 & 0.981 & $<0.0001$ & 0.801 & 0.201 & 0.951 & 0.012 \\
\hline $\mathrm{P} 20$ & 0.977 & 0.922 & 0.994 & $<0.0001$ & 0.924 & 0.692 & 0.981 & $<0.0001$ \\
\hline $\mathrm{P} 21$ & 1.000 & - & - & - & 0.690 & -0.249 & 0.923 & 0.048 \\
\hline $\mathrm{P} 22$ & 0.878 & 0.576 & 0.965 & 0.001 & 0.921 & 0.682 & 0.980 & $<0.0001$ \\
\hline $\mathrm{P} 23$ & 0.894 & 0.631 & 0.969 & $<0.0001$ & 0.864 & 0.454 & 0.966 & 0.003 \\
\hline \multicolumn{9}{|c|}{ Active Transport } \\
\hline
\end{tabular}


Table 4. Results of categorical item-by-item test-retest reliability tests.

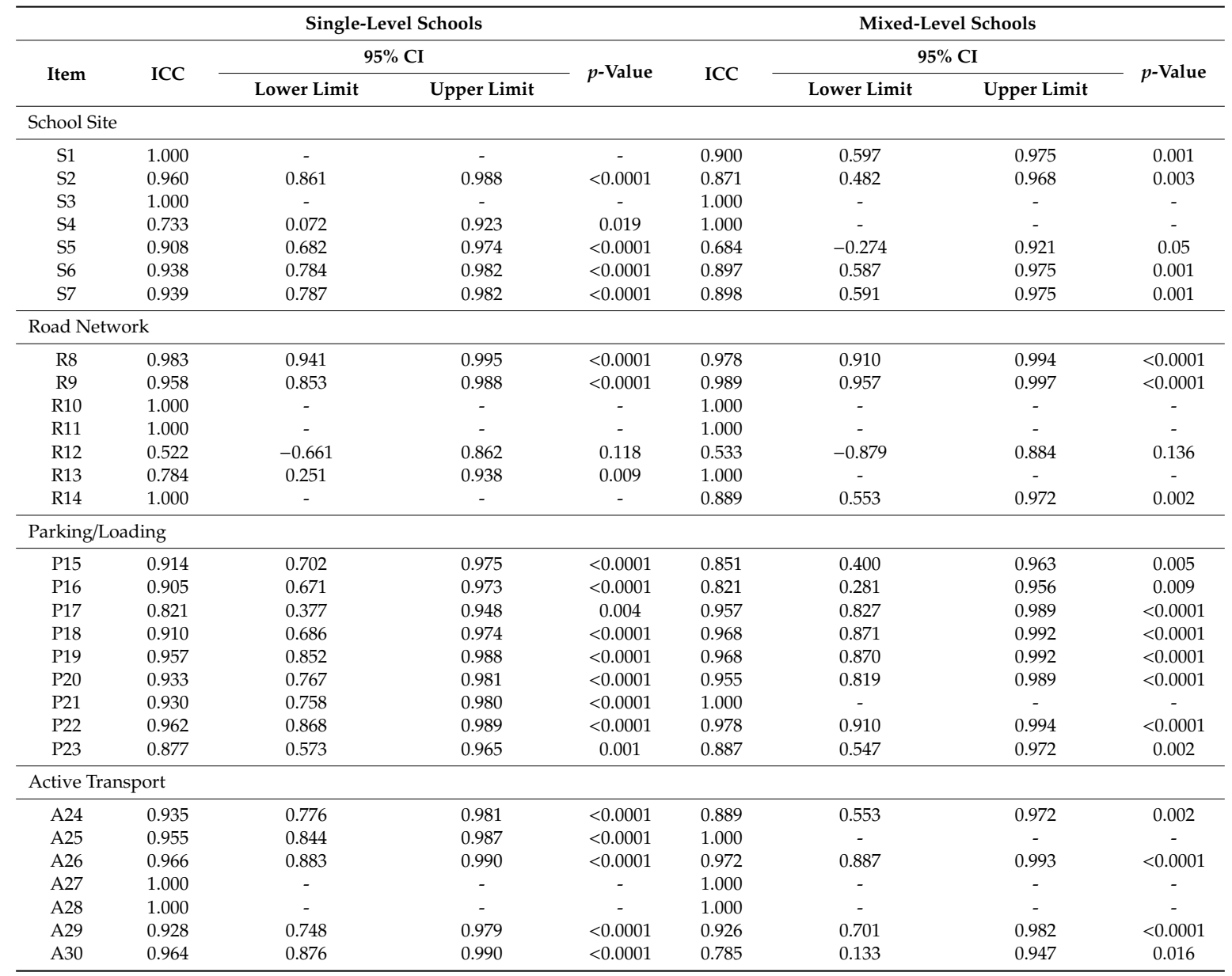

For mixed-level schools, the reliability statistical analysis also showed good to excellent results for both tests (see Tables 3 and 4). Most of the 30 item-by-item ICCs in inter-rater and test-retest tests received a score of 0.75 or more. Ratings of five items (fence around school, school zone signing and pavement markings, public bus accessibility, adequate bicycle storage, and availability of bike lanes) in the inter-rater test and nine items (land-use in the surrounding area, fence around school, speed reduction methods, road classification of the adjacent street, public bus accessibility, parking for high school students, connected crosswalks, availability of bicycle storage, and availability of bike lanes) in the test-retest test were in a complete match $(\mathrm{ICC}=1)$.

\section{Qualitative Assessment of Schools}

\subsection{Scores and Assessment of Schools}

The results of the qualitative assessment of each school and assessment category, along with the overall assessment were summarized in Table 5. In general, good (above 75\%) scores mostly appeared for school site and road network categories. However, most poor scores (between $25 \%$ and $49 \%$ ) were visible for active transport and some for parking/loading. Besides, none of the schools' ratings were found to be undesirable (below 24\%). In short, active transport items needed the most attention for schools in Qatar. 
Table 5. Overall scores of the schools in Qatar based on education level.

\begin{tabular}{|c|c|c|c|c|c|c|c|c|c|c|}
\hline \multirow{2}{*}{ Level * } & \multicolumn{2}{|c|}{ School Site } & \multicolumn{2}{|c|}{ Road Network } & \multicolumn{2}{|c|}{ Parking/Loading } & \multicolumn{2}{|c|}{ Active Transport } & \multicolumn{2}{|c|}{ Overall Assessment } \\
\hline & $\%$ & Quality & $\%$ & Quality & $\%$ & Quality & $\%$ & Quality & $\%$ & Quality \\
\hline 1 & 82 & Good & 80 & Good & 77 & Good & 58 & Acceptable & 74 & Acceptable \\
\hline 3 & 64 & Acceptable & 59 & Acceptable & 55 & Acceptable & 34 & Poor & 53 & Acceptable \\
\hline 1,2 & 67 & Acceptable & 64 & Acceptable & 61 & Acceptable & 60 & Acceptable & 63 & Acceptable \\
\hline 2,3 & 69 & Acceptable & 55 & Acceptable & 42 & Poor & 32 & Poor & 49 & Poor \\
\hline
\end{tabular}

Note: $0-24 \%$ = Undesirable, $25-49 \%=$ Poor, $50-74 \%=$ Acceptable, and $75-100 \%=$ Good. ${ }^{*} 1=$ Elementary, $2=$ Middle, 3 = High.

Furthermore, schools in Qatar differ based on the different education levels they offer due to the limitation of resources, the number of expected students, objectives, and so on. As students in elementary, middle, and high schools have different needs and requirements due to varying age ranges, their assessment results were also expected to differ. Table 6 shows the scores based on the education level. Elementary schools scored the highest overall score followed by middle, elementary/middle, and elementary/middle/high schools. High schools scored lower than elementary and middle schools. Again, the active transport category scored the highest number of poor assessments across education levels except for elementary and elementary/middle schools. Overall, the school site category scored the best $(75 \%)$ across all school types followed by road network (67\%), parking/loading $(62 \%)$, and active transport $(47 \%)$ categories. As such, active transport items received the lowest score and require the most attention and pertinent improvements.

\subsection{Assessment Distribution of Schools}

The previous section summarized the percent scores the different types of schools received across the four categories. In this section, the percent distributions of the schools across various assessments are illustrated in Figure 2. The figure shows the comparison of percent school distributions across education levels. The assessment distribution figure provides a better comparison of the schools in Doha across the categories since the number of schools for each school type was not the same.

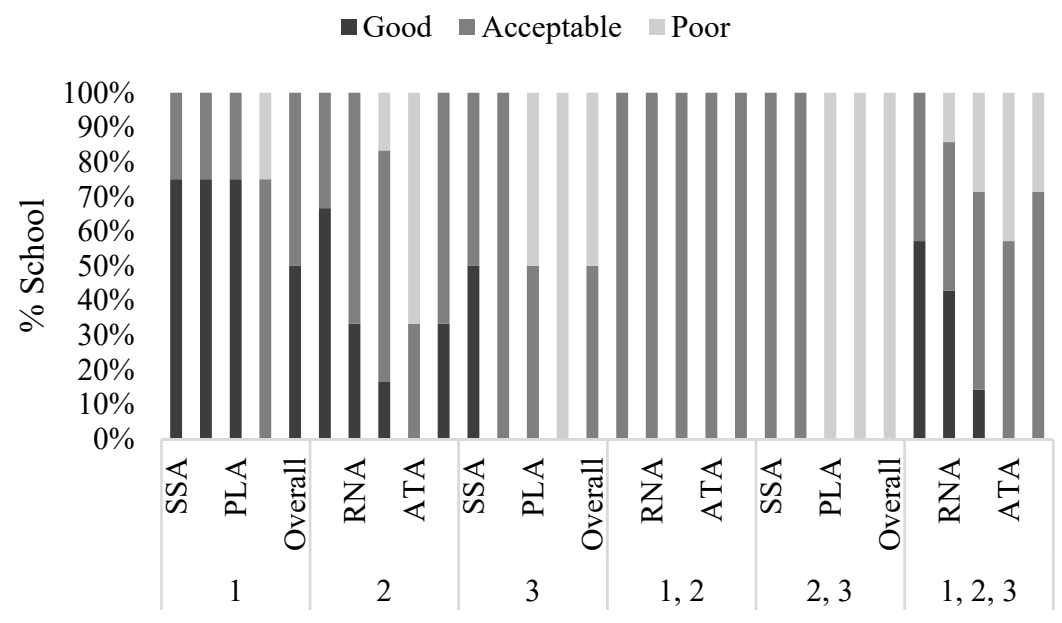

Figure 2. Comparison of percent school distribution between education levels. Education Level $(1=$ Elementary, 2 = Middle, 3 = High). Assessment Category (SSA = School site, RNA = Road network, PLA $=$ Parking/Loading, ATA = Active Transport). 
Table 6. Mean percent scores of the audit items in the SAT for the sample schools in Doha, Qatar.

\begin{tabular}{|c|c|c|c|c|c|c|c|c|}
\hline Item & Description & $\begin{array}{l}\text { All } \\
(\%)\end{array}$ & $\begin{array}{c}1 \\
(\%)\end{array}$ & $\begin{array}{c}2 \\
(\%)\end{array}$ & $\begin{array}{c}3 \\
(\%)\end{array}$ & $\begin{array}{l}1,2 \\
(\%)\end{array}$ & $\begin{array}{l}2,3 \\
(\%)\end{array}$ & $\begin{array}{c}1,2,3 \\
(\%)\end{array}$ \\
\hline A28 & Bike lane & 25 & 25 & 25 & 25 & 25 & 25 & 25 \\
\hline $\mathrm{A} 27$ & Adequate bicycle storage & 27 & 25 & 25 & 33 & 25 & 25 & 29 \\
\hline $\mathrm{R} 13$ & Public bus accessibility & 31 & 38 & 25 & 42 & 25 & 25 & 32 \\
\hline P17 & Parking for service \& emergency vehicles & 40 & 63 & 28 & 25 & 25 & 25 & 48 \\
\hline $\mathrm{R} 14$ & Amenities for physically challenged students & 45 & 44 & 64 & 54 & 25 & 25 & 35 \\
\hline A29 & Separation of travel modes & 45 & 46 & 50 & 25 & 33 & 50 & 49 \\
\hline S7 & Congestion problems & 53 & 63 & 51 & 42 & 54 & 33 & 54 \\
\hline P16 & Adequate queuing area & 54 & 52 & 60 & 54 & 50 & 33 & 54 \\
\hline $\mathrm{P} 20$ & Safety of parents & 55 & 88 & 46 & 50 & 58 & 25 & 50 \\
\hline $\mathrm{P} 23$ & Parking problems & 56 & 71 & 58 & 33 & 79 & 33 & 49 \\
\hline $\mathrm{A} 24$ & Walking and biking conditions & 56 & 71 & 50 & 42 & 71 & 50 & 54 \\
\hline $\mathrm{A} 26$ & Availability of crosswalk & 57 & 73 & 44 & 54 & 83 & 25 & 56 \\
\hline $\mathrm{A} 30$ & Pedestrian problems & 60 & 73 & 58 & 25 & 88 & 25 & 61 \\
\hline $\mathrm{S} 2$ & Presence of major road & 60 & 67 & 75 & 50 & 38 & 67 & 52 \\
\hline A25 & Connected crosswalks & 63 & 92 & 51 & 33 & 96 & 25 & 60 \\
\hline $\mathrm{R} 8$ & Speed limit signs & 63 & 98 & 38 & 58 & 88 & 25 & 64 \\
\hline P19 & Visitor parking & 64 & 83 & 67 & 58 & 54 & 42 & 58 \\
\hline $\mathrm{P} 22$ & Traffic organization duty & 64 & 79 & 58 & 63 & 58 & 25 & 69 \\
\hline S5 & Location of entrance & 64 & 75 & 68 & 54 & 42 & 42 & 68 \\
\hline R9 & School sign \& pavement marking & 67 & 96 & 64 & 42 & 63 & 25 & 67 \\
\hline P15 & Adequate parking \& drop off space & 76 & 88 & 82 & 58 & 79 & 75 & 68 \\
\hline S6 & Multiple access to school & 79 & 79 & 78 & 67 & 100 & 58 & 80 \\
\hline P18 & Staff parking & 83 & 90 & 82 & 96 & 83 & 75 & 79 \\
\hline R11 & Road classification of adjacent street & 87 & 96 & 96 & 63 & 63 & 100 & 86 \\
\hline S3 & Land-use in surrounding area & 88 & 100 & 90 & 75 & 75 & 100 & 85 \\
\hline $\mathrm{R} 12$ & Adequate sight distance & 89 & 92 & 92 & 83 & 88 & 83 & 88 \\
\hline S1 & Proximity to high-speed roadway & 91 & 94 & 100 & 79 & 63 & 100 & 92 \\
\hline R10 & Speed reduction methods & 91 & 96 & 99 & 71 & 100 & 100 & 85 \\
\hline S4 & Fence around school & 94 & 94 & 90 & 83 & 100 & 83 & 99 \\
\hline
\end{tabular}

0-24\% = Undesirable, 25-49\% = Poor, 50-74\% = Acceptable, and 75-100\% = Good; 1 = Elementary, 2 = Middle, and $3=$ High.

Overall, elementary schools were equally divided into $75 \%$ good and $25 \%$ acceptable scores for all categories except for active transport. For active transport, the scores were the lowest among the four categories and divided between $75 \%$ acceptable and $25 \%$ poor. This pattern was found to be closely repeated by middle schools. The majority of middle schools were found to score good for the school site, road network, and parking/loading. However, the results of active transport were worse than the other three categories with 33\% acceptable and 67\% poor. In the case of high schools, for school site, $50 \%$ of the schools scored good and 50\% scored acceptable. In addition, 50\% of high schools scored acceptable for parking/loading and 50\% scored poor. However, all of the high schools scored poor for active transport.

For mixed schools, all elementary-middle schools scored acceptable across all domains. In addition, the middle-high school scored acceptable for school site and road network items and poor for parking/load and active transport items leading to an overall score of poor. Lastly, the mixed schools comprising of all education levels scored good for school site $(57 \%)$ followed by road network $(43 \%)$ and parking/loading $(14 \%)$. These schools scored the least for active transport with $57 \%$ acceptable score and $43 \%$ poor score. To sum up, for mixed schools, active transport scored the lowest and in need of most improvements.

\subsection{Scores of Audit Items}

The school assessment results discussed in the previous sections were based on the mean scores of the audit items in the school audit (excluding the item related to parking for high school students) and 
rated by the auditors for each of the sampled schools. The overall mean percent scores of the 29 audit items are illustrated in Figure 3 in ascending order. Likewise, the overall and the mean percent scores of the audit items for each school type based on education level are summarized in Table 6. The audit items in this table are also sorted based on ascending overall mean percent scores. The priority of the items requiring the most attention, as obtained from Figure 3 and Table 6, is indicative of how active transport items have received the least attention compared to the other elements of the school sites.



Figure 3. Mean percent score distribution of the audit items.

Out of six items that scored poor, three items were related to active transport (availability bike lane $(25 \%)$, adequate bicycle parking $(27 \%)$, and separation of travel modes $(45 \%))$. Additional poor items included two road network items (public bus accessibility $(31 \%)$ and amenities for physically challenged students (45\%)), and one parking/loading item (parking for service and emergency vehicles $(40 \%))$. All remaining active transport items received acceptable scores with $63 \%$ for connected crosswalks, $60 \%$ for pedestrian problems, $57 \%$ for availability of crosswalk, and $56 \%$ for walking and biking conditions. In general, no active transport items received good score. Furthermore, the mean percent scores of the active transport items under each school type were mostly similar to the overall percent scores of the active transport items.

\section{Discussion}

Infrastructure around schools is one of the important factors in increasing children's likelihood of walking or cycling to school. The purpose of this study was to assess the infrastructure and environment around schools in the city of Doha, Qatar with a special emphasis on active transport (walking and cycling). The primary objective was to identify strengths and weaknesses and provide recommendations for overall and specific improvements. A comprehensive audit tool was used to achieve this objective. The tool has well-defined scales to convert qualitative evaluation of existing school sites into a quantitative assessment. It includes a 30-item checklist categorized into four domains: school site assessment, road network assessment, parking/loading assessment, and active transport assessment. Th used tool is more comprehensive than the few school audit tools available in the literature $[24,26]$. The tool was validated with inter-rater and test-retest reliability tests. The overall results of the reliability tests indicated an overall good to excellent level of reproducibility. However, like previous studies, the overall reliabilities of the test-retest tests were higher than the results of the inter-rater tests [36-38].

In general, the overall assessment of the schools revealed acceptable scores. The school site category received the best scores. The road network and parking/loading categories received acceptable 
scores. The results indicated that most of the active transport items scored poor, requiring the most improvements. Thus, significantly increasing the quality of these items could significantly elevate the overall quality of the infrastructure around schools in Qatar. A detailed analysis was conducted based on school type (elementary, middle, high, and mixed-schools). Elementary schools scored acceptable for active transport items. However, middle, high, and most of the mixed schools showed poor scores for these items. This was somewhat an indicator that public authorities need to consider improving active transport items at most of the schools. Such improvements could encourage more children to walk or cycle to school instead of being primarily dropped-off and picked up by their parents' vehicles or school buses. The analysis also revealed that adding bike lanes, ensuring adequate bicycle parking, and providing good separation of travel modes are the most needed improvements at school sites. Furthermore, additional items such as proper signs and pavement markings, safe crossings, well-connected sidewalks around school sites need to be provided or improved so that students are encouraged to walk or cycle to school and their parents are less concerned about their safety.

It is important to note that this study only assessed one aspect related to improving active transportation. Future studies are needed to explore other barriers that school children and parents experience. Although it was important to identify such weakness, improving the infrastructure may not necessarily increase active transportation since other factors including personal and social factors can also affect children's decision to walk and cycle to school [39]. Some of these factors include the education level of parents, car ownership, availability of school buses, personal barriers, positive attitude of children/parents, support of peers, and walking regularly.

In summary, there has been a general decline in the percentage of children who walked or biked to school [40]. Along with this decline, more children have become obese [41,42]. As a result of childhood obesity, the risks of developing serious short-term disease and chronic health issues as a child and then as an adult increase [43-52]. There is evidence that early interventions by schools, public agencies, and private organizations could help reverse the obesity epidemic by providing an environment that teaches and encourages young children to adopt a healthy and life-long active lifestyle [53,54]. Studies show that children who walk or cycle to school have been associated with increased levels of physical activity and better health [55-57]. Furthermore, physical education and activity combined with good nutrition and programs have been linked with positive academic performance in children [54]. Therefore, improvements in personal, social, and infrastructure factors may encourage more students to walk or bike to schools and improve problems related to childhood obesity and physical activity.

Author Contributions: Conceptualization, K.S.; Methodology, K.S.; Data Curation, K.S. and K.A.-R.; Formal Analysis, K.S. and K.A.-R.; Writing-Original Draft, K.S. and K.A.-R.; Writing-Review and Editing, K.S. and K.A.-R. All authors have read and agreed to the published version of the manuscript.

Funding: This research received no external funding.

Acknowledgments: We would like to thank the reviewers for their useful comments and suggestions.

Conflicts of Interest: The authors declare no conflict of interest.

\section{References}

1. Centers for Disease Control and Prevention. Children's Health and the Built Environment. 2009. Available online: https://www.cdc.gov/healthyplaces/healthtopics/children.htm (accessed on 10 December 2020).

2. Gallimore, J.M.; Brown, B.B.; Werner, C.M. Walking routes to school in new urban and suburban neighborhoods: An environmental walkability analysis of blocks and routes. J. Environ. Psychol. 2011, 31, 184-191. [CrossRef]

3. Masoumi, H.E. Associations of built environment and children's physical activity: A narrative review. Rev. Environ. Health 2017, 32, 315-331. [CrossRef] [PubMed]

4. Timperio, A.; Crawford, D.; Telford, A.; Salmon, J. Perceptions about the local neighborhood and walking and cycling among children. Prev. Med. 2004, 38, 39-47. [CrossRef]

5. Carlin, J.B.; Stevenson, M.R.; Roberts, I.; Bennett, C.M.; Gelman, A.; Nolan, T. Walking to school and traffic exposure in Australian children. Aust. N. Z. J. Public Health 1997, 21, 286-292. [CrossRef] [PubMed] 
6. Giles-Corti, B.; Wood, G.; Pikora, T.; Learnihan, V.; Bulsara, M.; Van Niel, K.; Timperio, A.; McCormack, G.; Villanueva, K. School site and the potential to walk to school: The impact of street connectivity and traffic exposure in school neighborhoods. Health Place 2011, 17, 545-550. [CrossRef] [PubMed]

7. Christiansen, L.B.; Toftager, M.; Schipperijn, J.; Ersbøll, A.K.; Giles-Corti, B.; Troelsen, J. School site walkability and active school transport-Association, mediation and moderation. J. Transp. Geogr. 2014, 34, 7-15. [CrossRef]

8. Shaaban, K.; Muley, D. Investigation of weather impacts on pedestrian volumes. Transp. Res. Procedia 2016, 14, 115-122. [CrossRef]

9. Shaaban, K.; Muley, D.; Elnashar, D. Temporal variation in walking behavior: An empirical study. Case Stud. Transp. Policy 2017, 5, 671-680. [CrossRef]

10. Shaaban, K.; Muley, D.; Elnashar, D. Evaluating the effect of seasonal variations on walking behaviour in a hot weather country using logistic regression. Int. J. Urban Sci. 2018, 22, 382-391. [CrossRef]

11. Shaaban, K. Assessing sidewalk and corridor walkability in developing countries. Sustainability 2019, 11, 3865. [CrossRef]

12. Shaaban, K. Why don't people ride bicycles in high-income developing countries, and can bike-sharing be the solution? The case of Qatar. Sustainability 2020, 12, 1693. Available online: https://www.mdpi.com/20711050/12/4/1693 (accessed on 19 March 2020). [CrossRef]

13. Shaaban, K.; Siam, A.; Badran, A.; Shamiyah, M. A simple method to assess walkability around metro stations. Int. J. Sustain. Soc. 2018, 10, 1-19. [CrossRef]

14. Abdella, G.M.; Shaaban, K. Modeling the impact of weather conditions on pedestrian injury counts using LASSO-based poisson model. Arab. J. Sci. Eng. 2020, 1-12. [CrossRef]

15. Shaaban, K.; Wood, J.S.; Gayah, V.V. Investigating driver behavior at minor-street stop-controlled intersections in Qatar. Transp. Res. Rec. 2017, 2663, 109-116. [CrossRef]

16. Ghanim, M.S.; Shaaban, K. A case study for surrogate safety assessment model in predicting real-life conflicts. Arab. J. Sci. Eng. 2019, 44, 4225-4231. [CrossRef]

17. Shaaban, K.; Pande, A. Classification tree analysis of factors affecting parking choices in Qatar. Case Stud. Transp. Policy 2016, 4, 88-95. [CrossRef]

18. Henry, K.; Younossi, O.; Al-Dafa, M.; Culbertson, S.; Mattock, M.G. Qatar's School Transportation System-Supporting Safety, Efficacy, and Service Quality; Rand Corporation: Santa Monica, CA, USA, 2012.

19. Centers for Disease Control and Prevention. Strategies to Prevent Obesity and Other Chronic Diseases: The CDC Guide to Strategies to Increase Physical Activity in the Community; United States Department of Health and Human Services: Washington, DC, USA, 2011; pp. 1-56.

20. Garrard, J. Active Transport: Children and Young People; VicHealth: Carlton South, Australia, 2009; p. 20.

21. Heath, G.W.; Brownson, R.C.; Kruger, J.; Miles, R.; Powell, K.E.; Ramsey, L.T. The effectiveness of urban design and land use and transport policies and practices to increase physical activity: A systematic review. J. Phys. Act. Health 2006, 3 (Suppl. 1), S55-S76. [CrossRef]

22. Macbeth, A.G. Bicycle lanes in Toronto. Inst. Transp. Eng. J. 1999, 69, 38-40.

23. Transportation Research Board; Institute of Medicine; Committee on Physical Activity, Health, Transportation and Land Use. Does the Built Environment Influence Physical Activity?: Examining the Evidence; National Academies Press: Washington, DC, USA, 2005.

24. Lee, C.; Kim, H.J.; Dowdy, D.M.; Hoelscher, D.M.; Ory, M.G. TCOPPE school environmental audit tool: Assessing safety and walkability of school environments. J. Phys. Act. Health 2013, 10, 949. [CrossRef]

25. Napier, M.A.; Brown, B.B.; Werner, C.M.; Gallimore, J. Walking to school: Community design and child and parent barriers. J. Environ. Psychol. 2011, 31, 45-51. [CrossRef]

26. Tarun, S.; Arora, M.; Rawal, T.; Benjamin Neelon, S.E. An evaluation of outdoor school environments to promote physical activity in Delhi, India. BMC Public Health 2017, 17, 1-9. [CrossRef] [PubMed]

27. Van Sluijs, E.M.F.; Skidmore, P.M.L.; Mwanza, K.; Jones, A.P.; Callaghan, A.M.; Ekelund, U.; Harrison, F.; Harvey, I.; Panter, J.R.; Wareham, N.J.; et al. Physical activity and dietary behaviour in a population-based sample of British 10-year old children: The SPEEDY study (Sport, Physical activity and Eating behaviour: Environmental Determinants in Young people). BMC Public Health 2008, 8, 1-12. [CrossRef]

28. Jones, N.R.; Jones, A.; van Sluijs, E.M.F.; Panter, J.; Harrison, F.; Griffin, S.J. School environments and physical activity: The development and testing of an audit tool. Health Place 2010, 16, 776-783. [CrossRef] [PubMed] 
29. Zhu, X.; Lee, C. Walkability and safety around elementary schools. Economic and ethnic disparities. Am. J. Prev. Med. 2008, 34, 282-290. [CrossRef]

30. Moudon, A.V.; Lee, C. Walking and bicycling: An evaluation of environmental audit instruments. Am. J. Health Promot. 2003, 18, 21-37. [CrossRef] [PubMed]

31. Lee, C.; Moudon, A.V. Physical activity and environment research in the health field: Implications for urban and transportation planning practice and research. J. Plan. Lit. 2004, 19, 147-181. [CrossRef]

32. Shaaban, K.; Abdur-Rouf, K. Development, validation, and application of School Audit Tool (SAT): An effective instrument for assessing traffic safety and operation around schools. Sustainability 2019, 11, 6438. [CrossRef]

33. Ministry of Education and Higher Education. Admissions Policy; Qatar Government: Doha, Qatar, 2018.

34. Hallgren, K.A. Computing inter-rater reliability for observational data: An overview and tutorial. Tutor. Quant. Methods Psychol. 2012, 8, 23-34. [CrossRef]

35. Cicchetti, D.V. Guidelines, criteria, and rules of thumb for evaluating normed and standardized assessment instruments in psychology. Psychol. Assess. 1994, 6, 284-290. [CrossRef]

36. Pikora, T.J.; Bull, F.C.L.; Jamrozik, K.; Knuiman, M.; Giles-Corti, B.; Donovan, R.J. Developing a reliable audit instrument to measure the physical environment for physical activity. Am. J. Prev. Med. 2002, 23, 187-194. [CrossRef]

37. Boarnet, M.G.; Day, K.; Alfonzo, M.; Forsyth, A.; Oakes, M. The Irvine-Minnesota inventory to measure built environments: Reliability tests. Am. J. Prev. Med. 2006, 30, 153-159. [CrossRef] [PubMed]

38. Brownson, R.C.; Hoehner, C.M.; Brennan, L.K.; Cook, R.A.; Elliott, M.B.; McMullen, K.M. Reliability of 2 instruments for auditing the environment for physical activity. J. Phys. Act. Health 2004, 1, 191-208. [CrossRef]

39. Zhu, X.; Arch, B.; Lee, C. Personal, social, and environmental correlates of walking to school behaviors: Case study in Austin, Texas. Sci. World J. 2008, 8, 859-872. [CrossRef] [PubMed]

40. McDonald, N.C. Active transportation to school: Trends among U.S. schoolchildren, 1969-2001. Am. J. Prev. Med. 2007, 32, 509-516. [CrossRef] [PubMed]

41. LaFontaine, T. Physical activity: The epidemic of obesity and overweight among youth: Trends, consequences, and interventions. Am. J. Lifestyle Med. 2008, 2, 30-36. [CrossRef]

42. Ogden, C.L.; Carroll, M.D.; Lawman, H.G.; Fryar, C.D.; Kruszon-Moran, D.; Kit, B.K.; Flegal, K.M. Trends in obesity prevalence among children and adolescents in the United States, 1988-1994 through 2013-2014. JAMA 2016, 315, 2292. [CrossRef]

43. National Center for Chronic Disease Prevention and Health Promotion. Childhood Obesity Facts. 2018. Available online: https://www.cdc.gov/obesity/data/childhood.html (accessed on 10 December 2020).

44. Bagchi, K. Nutrition in the eastern Mediterranean region of the World Health Organization. East. Mediterr. Health J. 2008, 14, S107-S113.

45. Ng, S.W.; Zaghloul, S.; Ali, H.I.; Harrison, G.; Popkin, B.M. The prevalence and trends of overweight, obesity and nutrition-related non-communicable diseases in the Arabian Gulf States. Obes. Rev. 2011, 12, 1-13. [CrossRef]

46. Seth, A.; Sharma, R. Childhood obesity. Indian J. Pediatr. 2013, 80, 309-317. [CrossRef]

47. McGuire, S. Accelerating progress in obesity prevention: Solving the weight of the nation. Adv. Nutr. 2012, 3, 708-709. [CrossRef]

48. Must, A.; Hollander, S.A.; Economos, C.D. Childhood obesity: A growing public health concern. Expert Rev. Endocrinol. Metab. 2006, 1, 233-254. [CrossRef]

49. Freedman, D.S.; Mei, Z.; Srinivasan, S.R.; Berenson, G.S.; Dietz, W.H. Cardiovascular risk factors and excess adiposity among overweight children and adolescents: The Bogalusa Heart Study. J. Pediatr. 2007, 150, 12-17.e2. [CrossRef] [PubMed]

50. Hoelscher, D.M.; Kirk, S.; Ritchie, L.; Cunningham-Sabo, L. Position of the Academy of Nutrition and Dietetics: Interventions for the prevention and treatment of pediatric overweight and obesity. J. Acad. Nutr. Diet. 2013, 113, 1375-1394. [CrossRef] [PubMed]

51. May, A.; Kuklina, E.; Yoon, P. Prevalence of cardiovascular disease risk factors among US adolescents, 1999-2008. Am. Acad. Pediatr. 2012, 129, 1035-1041. [CrossRef] [PubMed]

52. Benjamin, R.M. Surgeon general's perspectives. Public Health Rep. 2010, 125, 514-515. [CrossRef] [PubMed]

53. Kerkadi, A.; Hassan, A.S.; Eltayeb, M.; Yousef, A. High prevalence of the risk of overweight and overweight among Qatari children ages 9 through 11. Nutr. Food Sci. 2009, 39, 36-45. [CrossRef] 
54. Centers for Disease Control and Prevention. Make a Difference at Your School! 2017. Available online: https://eric.ed.gov/?id=ED505189 (accessed on 10 December 2020).

55. Lee, M.C.; Orenstein, M.R.; Richardson, M.J. Systematic review of active commuting to school and children's physical activity and weight. J. Phys. Act. Health 2008, 5, 930-949. [CrossRef]

56. Ozdemir, A.; Yilmaz, O. Assessment of outdoor school environments and physical activity in Ankara's primary schools. J. Environ. Psychol. 2008, 28, 287-300. [CrossRef]

57. Sallis, J.F.; Cervero, R.B.; Ascher, W.; Henderson, K.A.; Kraft, M.K.; Kerr, J. An ecological approach to creating active living communities. Annu. Rev. Public Health 2006, 27, 297-322. [CrossRef]

Publisher's Note: MDPI stays neutral with regard to jurisdictional claims in published maps and institutional affiliations.

(C) 2020 by the authors. Licensee MDPI, Basel, Switzerland. This article is an open access article distributed under the terms and conditions of the Creative Commons Attribution (CC BY) license (http://creativecommons.org/licenses/by/4.0/). 